\title{
In vivo pharmacokinetic/Pharmacodynamic modeling of Enrofloxacin against Escherichia coli in broiler chickens
}

\author{
Xia Xiao ${ }^{1,2,3}$, Lijie Jiang ${ }^{1}$, Weixuan Lan ${ }^{1}$, Yongjia Jiang ${ }^{1}$ and Zhiqiang Wang ${ }^{1,2,3^{*}}$ (D)
}

\begin{abstract}
Background: Systemic Escherichia coli infections cause early mortality of commercial broiler chickens. Although enrofloxacin has long been used in poultry, the in vivo pharmacokinetic/pharmacodynamic (PK/PD) relationship of enrofloxacin against $E$. coli is unclear. The present study aimed to establish an in vivo PK/PD model of enrofloxacin against $E$. coli in seven-day-old chicks and to ascertain whether the selection of target organ for PD determination is critical for parameter magnitude calculation in enrofloxacin PK/PD modeling.

Results: The in vivo effectiveness of enrofloxacin against $E$. coli in different organs varied, with the $E_{\text {max }}$ ranging from 4.4 to $-5.8 \log _{10}$ colony forming units (cfu)/mL or cfu/g. Both the surrogate $A_{U C} C_{0-24} / M_{I C}$ of enrofloxacin or $A \cup C_{0-24} /$ MIC of the combination of enrofloxacin and ciprofloxacin correlated well with effectiveness in each organ. The AUC ${ }_{0-}$ ${ }_{24} / \mathrm{MIC}$ ratio of the combination of enrofloxacin and ciprofloxacin producing bactericidal and elimination effects were 21.29 and 32.13 in blood; 41.68, and 58.52 in the liver; and 27.65 and 46.22 in the lung, respectively.

Conclusions: The in vivo effectiveness of enrofloxacin against $E$. coli in different organs was not identical after administration of the same dosage. To describe the magnitude of PK/PD parameter exactly, bacterial loading reduction in different organs as PD endpoints should be evaluated and compared in PK/PD modeling. The selection of a target organ to evaluate PDs is critical for rational dosage recommendation.
\end{abstract}

Keywords: Escherichia coli, Enrofloxacin, In vivo, PK/PD modeling, Chicken

\section{Background}

It is estimated that $50 \%$ of total poultry loses could be attributed to first week mortalities [1]. Among them, over $50 \%$ of mortalities are caused by bacterial infections, primarily Escherichia coli [2]. Systemic E. coli infections contribute significantly to the early mortality of commercial broiler chickens [3]. However, because of the high diversity in virulence-associated genes and serotypes, effective vaccines against $E$. coli challenge are rare [4]. Until now, using antimicrobials has been the main strategy to control E. coli infections in the poultry industry.

\footnotetext{
* Correspondence: zqwang@yzu.edu.cn

'College of Veterinary Medicine, Yangzhou University, Yangzhou 225009, Jiangsu, People's Republic of China

${ }^{2}$ Jiangsu Co-innovation Center for Prevention and Control of Important Animal Infectious Diseases and Zoonoses, Yangzhou, Jiangsu 225009,

People's Republic of China

Full list of author information is available at the end of the article
}

Enrofloxacin, a second-generation fluoroquinolone, is commonly used in chickens because of its favorable pharmacokinetic (PK) profile and its excellent activity against gram-negative aerobic bacteria and some gram-positive bacteria $[5,6]$. However, with the extensive use of enrofloxacin, resistance has emerged [7]. Enrofloxacin is metabolized to ciprofloxacin, which is used clinically in humans, and there are reports showing that resistance genes for fluoroquinolones could transfer to other organisms under antimicrobial pressure $[8,9]$. Thus, the non-rational usage of enrofloxacin runs the risk of leading to bacterial resistance and potential health hazards in humans [10-12]. Thus, there is a growing need to optimize the use of enrofloxacin.

Optimizing the use of an antimicrobial should be based on a good understanding of its PK and pharmacodynamic (PD) relationship in target animals against specific bacterial species [13]. Although ex vivo PK/PD modeling of enrofloxacin has been evaluated in buffalo 
calves, swine, and chickens against E. coli, Pasteurella multocida, and Salmonella typhimurium [14-20], to the best of our knowledge, there are no in vivo PK/PD modeling studies of enrofloxacin against $E$. coli in chicks. In vivo $\mathrm{PK} / \mathrm{PD}$ modeling has great advantages over ex vivo modeling in describing the PK/PD relationship [21], especially for enrofloxacin, whose metabolite, ciprofloxacin, (another fluoroquinolone) has almost the same potency as enrofloxacin. Therefore, for PK/PD modeling of enrofloxacin, it is important to involve its metabolism to ciprofloxacin in the modeling. According to our previous study, the selection of the target organ for PD determination is critical for parameter magnitude calculation in antimicrobial PK/PD modeling [22]. Whether this is true for enrofloxacin requires further investigation.

In the present study, to further understand the PK/PD relationship of enrofloxacin, especially whether the selection of a target organ for PD determination is critical for parameter magnitude calculation in PK/PD modeling, broilers were used as an animal model. The following aspects were investigated: (1) The pharmacokinetics of enrofloxacin and its metabolism to ciprofloxacin were determined at three different dosage administrations; (2) the in vivo PK/PD modeling of enrofloxacin against $E$. coli was developed using the reductions in the bacterial burden in the blood, liver, and lung as the PD endpoints; (3) whether the concentration of ciprofloxacin influence the in vivo $\mathrm{PK} / \mathrm{PD}$ modeling of enrofloxacin was evaluated; and (4) the corresponding magnitude of PK/PD parameters for a certain efficacy were determined.

\section{Results}

\section{In vitro susceptibility}

The MICs of enrofloxacin and ciprofloxacin against $E$. coli $\mathrm{O} 78$ were the same $(0.5 \mu \mathrm{g} / \mathrm{mL})$. The corresponding $\mathrm{MBC}$ values were 0.5 and $1 \mu \mathrm{g} / \mathrm{mL}$ respectively. The MIC and MBC of enrofloxacin in serum were identical $(0.5 \mu \mathrm{g} / \mathrm{mL})$. The MPC of enrofloxacin was $3.2 \mu \mathrm{g} / \mathrm{mL}$ (Table 1).

Table $1 \mathrm{MIC}$ and MPC values $(\mu \mathrm{g} / \mathrm{mL}$ ) of enrofloxacin and ciprofloxacin against E. coli $\mathrm{O} 78$ in Mueller-Hinton broth and serum

\begin{tabular}{llll}
\hline Parameters $(\mu \mathrm{g} / \mathrm{mL})$ & ENR (broth) & ENR (serum) & CIP (broth) \\
\hline MIC & 0.5 & 0.5 & 0.5 \\
MBC & 0.5 & 0.5 & 1 \\
MPC & 3.2 & - & - \\
\hline
\end{tabular}

MIC minimum inhibitory concentration, MPC mutant prevention concentration, $M B C$ minimum bactericidal concentration, ENR enrofloxacin, CIP ciprofloxacin

\section{E. coli infection model}

Clinical signs of colibacillosis, such as depression, decreased feeding, diarrhea, and fever were observed 24 h after challenge with $E$. coli O78. After dissection, perihepatitis and pericarditis were obvious. The bacteria load in the blood, liver, and lung were $7.2 \pm 0.92 \log _{10} \mathrm{cfu} /$ $\mathrm{mL}, 6.4 \pm 0.14 \log _{10} \mathrm{cfu} / \mathrm{g}$, and $6.1 \pm 0.17 \log _{10} \mathrm{cfu} / \mathrm{g}$ respectively. The bacterial load in the three organs was similar among different chicks. The death rate was $10 \%$.

\section{Pharmacokinetics}

The serum drug concentration-time profiles of enrofloxacin and ciprofloxacin after enrofloxacin administration at three dosages are illustrated in Fig. 1 and Fig. 2. The PK parameters of enrofloxacin and ciprofloxacin are shown in Table 2 and Table 3. The time of peak concentration $\left(\mathrm{T}_{\max }\right)$ for enrofloxacin and ciprofloxacin were about 3.3 3.4 h and $4.3 \sim 5 \mathrm{~h}$, respectively, with peak concentrations $\left(C_{\max }\right)$ of $0.16,1.76$, and $2.86 \mu \mathrm{g} / \mathrm{mL}$ for enrofloxacin at 1,10 , and $20 \mathrm{mg} / \mathrm{kg}$, respectively; and of $0.03,0.10$, and $0.37 \mu \mathrm{g} / \mathrm{mL}$ at corresponding doses for ciprofloxacin. The $\mathrm{C}_{\max }$ of ciprofloxacin was much lower and emerged later than enrofloxacin. The $\mathrm{AUC}_{0-24}$ of enrofloxacin at 1,10 , and $20 \mathrm{mg} / \mathrm{kg}$ b.w. was $1.64,17.95$, and $30.07 \mathrm{~h}$, respectively, and the corresponding values for ciprofloxacin were $0.61,1.42$, and $4.93 \mathrm{~h}$, respectively. The $\mathrm{AUC}_{0-24}$ values of enrofloxacin were 2.6, 12.6, and 6.09 times higher than those of ciprofloxacin at doses of 1,10 , and $20 \mathrm{mg} / \mathrm{kg}$ b.w. respectively. Dose proportionality was observed for the $\mathrm{AUC}_{0-24}$ of enrofloxacin and ciprofloxacin in the range of 1-20 $\mathrm{mg} / \mathrm{kg}$ with $\mathrm{r}^{2}$ of 0.9868 and 0.9035 , respectively. Thus, the $\mathrm{AUC}_{0-24}$ of other doses between 1 and 20 $\mathrm{mg} / \mathrm{kg}$ could be calculated.

\section{In vivo $\mathrm{PK} / \mathrm{PD}$ analysis}

The $\mathrm{AUC}_{0-24} / \mathrm{MIC}$ ratios of enrofloxacin against $E$. coli O78 for doses of $1,2,5,7.5,10,12.5,15$, and $20 \mathrm{mg} / \mathrm{kg}$ were $5.27,8.26,17.20,24.66,32.11,39.57,47.02$, and $61.93 \mathrm{~h}$ respectively. The corresponding $\mathrm{AUC}_{0-24} / \mathrm{MIC}$ values of ciprofloxacin were $0.36,0.82,2.2,3.35,4.50$, $5.65,6.80$, and $13.24 \mathrm{~h}$, respectively.

The relationships between the effectiveness (bacteria loading reduction) of enrofloxacin in different organs and PK/PD indices of enrofloxacin, or the combination of enrofloxacin and ciprofloxacin, are shown in Fig. 3 and Fig. 4. The surrogate $\mathrm{AUC}_{0-24} / \mathrm{MIC}$ correlated well with effectiveness in each organ, with $\mathrm{r}^{2}$ values greater than 0.85 . The in vivo effectiveness of enrofloxacin against $E$. coli in different organs varied, with $E_{\max }$ ranging from -4.4 to $-5.8 \log _{10} \mathrm{cfu} / \mathrm{mL}$. Using the PK of enrofloxacin for simulation, then the $\mathrm{AUC}_{0-24} / \mathrm{MIC}$ values of enrofloxacin for the bactericidal effect in the blood, liver, and lung were 19.32, 32.15, and 23.41, 


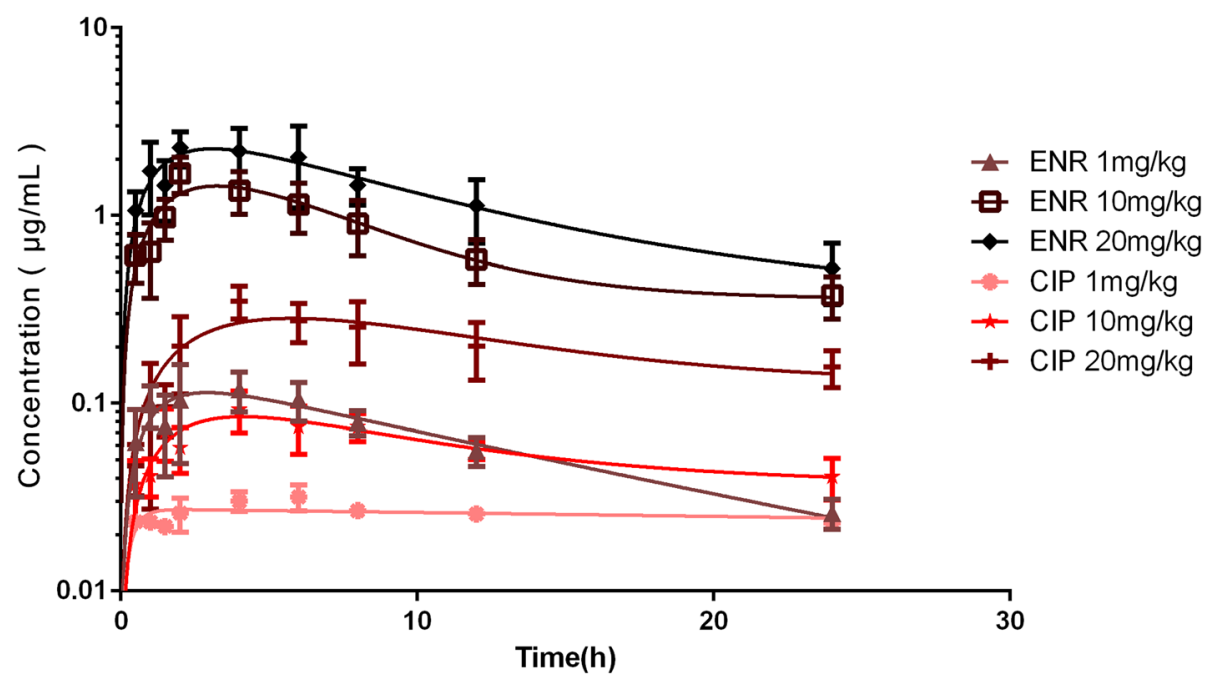

Fig. 1 The time-concentration profiles of enrofloxacin or ciprofloxacin in serum after oral administration of enrofloxacin at doses of 1, 10, and 20 $\mathrm{mg} / \mathrm{kg}$ in E. coli O78-infected chicks. [enrofloxacin (ENR); ciprofloxacin (CIP)]

respectively. The slopes were $2.58,2.36$, and 3.01 for the blood, liver, and lung, respectively (Table 4). Using the combined PK of enrofloxacin and ciprofloxacin for simulation, then the $\mathrm{AUC}_{0-24} / \mathrm{MIC}$ values for the bactericidal effect in the blood, liver, and lung were 21.29, 41.68 , and 27.65 , respectively (Table 5 ). The slopes were $4.19,2.67$, and 4.86 for the blood, liver, and lung, respectively.

\section{Discussion}

There are several infection routes for E. coli when simulating colibacillosis, such as intramuscular (IM) and oral administration [16, 23]. The complicated nature of the gastrointestinal tract could result in the bacterial load in different organs after oral administration being unstable. To obtain a stable bacterial concentration in the different organs, the IM infection route was chosen. In the present study, colibacillosis was achieved through inoculation of $\sim 10^{7} \mathrm{cfu} / \mathrm{mL}$ E. coli in chickens. However, the infection dose was lower than that used in a previous report [16], where colibacillosis was induced by oral gavage with $8 \mathrm{~mL}$ of $E$. coli culture containing $1.2 \times 10^{9} \mathrm{cfu} / \mathrm{mL}$. The differences in infection dose might be explained in two ways: The broilers used by Sang were 39 days old, whereas ours were 7 days old, and the inoculation method was different, oral gavage in Sang's report vs. IM injection in this study.

The PKs of enrofloxacin have been investigated in goats, pigs, calves, horses, and sheep [24-28]. It has also

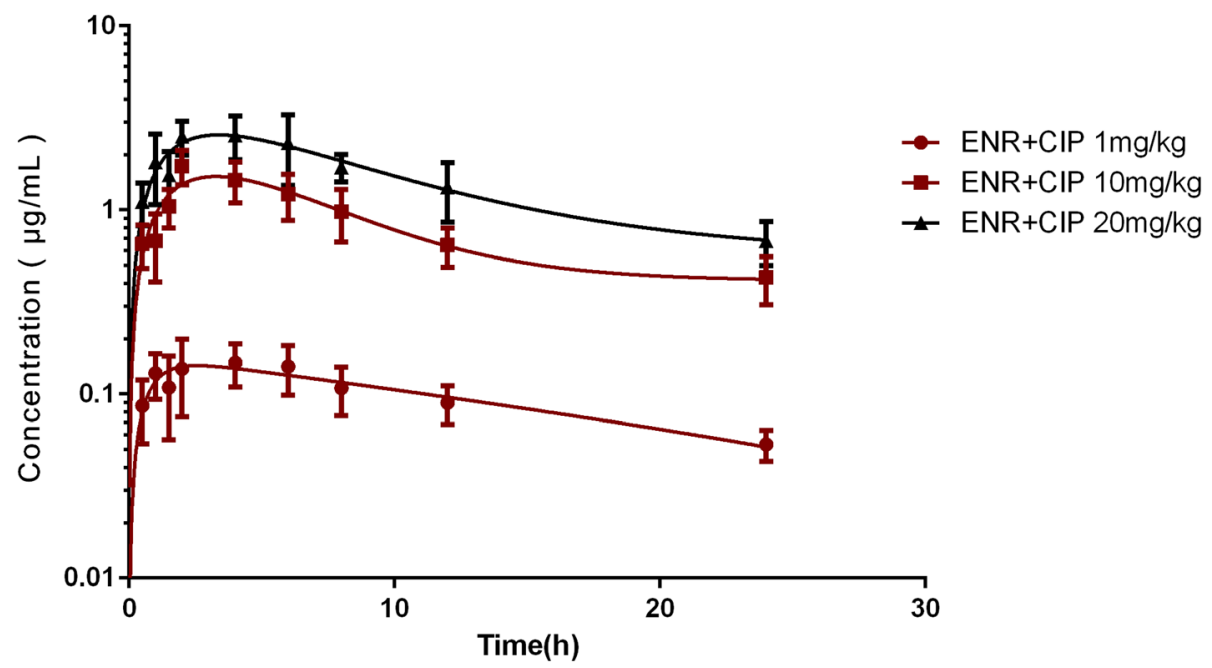

Fig. 2 The time-concentration profiles of the combination of enrofloxacin and ciprofloxacin in serum after oral administration of enrofloxacin at doses of 1, 10, and $20 \mathrm{mg} / \mathrm{kg}$ in E. coli O78-infected chicks. [enrofloxacin (ENR); ciprofloxacin (CIP)] 
Table 2 Pharmacokinetic parameters of enrofloxacin in serum after oral administration of 1, 10, and $20 \mathrm{mg} / \mathrm{kg}$ body weight enrofloxacin in E. coli O78-infected chicks (mean and SD, $n=10$ )

\begin{tabular}{llll}
\hline Parameters & $1 \mathrm{mg} / \mathrm{kg}$ & $10 \mathrm{mg} / \mathrm{kg}$ & $20 \mathrm{mg} / \mathrm{kg}$ \\
\hline $\mathrm{C}_{\max }(\mu \mathrm{g} / \mathrm{mL})$ & $0.16 \pm 0.041$ & $1.76 \pm 0.32$ & $2.86 \pm 0.52$ \\
$\mathrm{~T}_{\max }(\mathrm{h})$ & $3.35 \pm 1.8$ & $3.4 \pm 2.12$ & $3.3 \pm 1.77$ \\
$\mathrm{~T}_{1 / 2 \beta}(\mathrm{h})$ & $10.75 \pm 1.8$ & $11.44 \pm 1.41$ & $9.78 \pm 1.26$ \\
$\mathrm{AUC} \mathrm{C}_{0-24}(\mathrm{~h} \cdot \mu \mathrm{g} / \mathrm{mL})$ & $1.64 \pm 0.28$ & $17.95 \pm 2.45$ & $30.07 \pm 4.64$ \\
$\mathrm{CL} / \mathrm{F}(\mathrm{mL} / \mathrm{h} / \mathrm{kg})$ & $488 \pm 114$ & $420 \pm 85$ & $548 \pm 114$ \\
\hline
\end{tabular}

$C_{\text {max }}$ peak concentration, $T_{\max }$ time of peak concentration, $T_{1 / 2 \beta}$ elimination half-life, $A \cup C_{0-24}$ area under the concentration-time curve from 0 to $24 \mathrm{~h}, C L / F$ oral clearance

been studied in chickens [29-31]. The elimination half-life $\left(\mathrm{T}_{1 / 2 \beta}\right)$ values in this study $(9.78-11.4 \mathrm{~h})$ were similar to those in previous reports [30]. After oral administration of $10 \mathrm{mg} / \mathrm{kg}$ of enrofloxacin, the $\mathrm{AUC}_{0-24}$ value $(17.95 \mathrm{~h})$ in this study was much lower than that reported in previously $(35 \mathrm{~h}$ in Da Silva's report and 25.35 in Mekala's) [30, 32]. The difference illustrates that the pathological state affects the total amount of the drug in the blood. Although ciprofloxacin is the main active metabolite of enrofloxacin, few studies have reported the concentration of ciprofloxacin. Da Silva reported that the concentration of ciprofloxacin was lower than their limit of quantification (LOQ) $(0.2 \mu \mathrm{g} /$ $\mathrm{mL}$ ) in healthy chickens [30]. With an LOQ of $0.02 \mu \mathrm{g} /$ $\mathrm{mL}$, the concentration of ciprofloxacin in the present study was detected even after enrofloxacin administration at dose of $1 \mathrm{mg} / \mathrm{kg}$ b.w. The biotransformation of enrofloxacin to ciprofloxacin at doses of 10 and $20 \mathrm{mg} /$ $\mathrm{kg}$ b.w. were 7.9 and $15.3 \%$, which was in accordance with a previous study [16]. However, the biotransformation rate was as $37 \%$ higher for the low dose $(1 \mathrm{mg} / \mathrm{kg}$ b.w.). The moderate concentration of ciprofloxacin indicated that the role of ciprofloxacin should be considered in pharmacodynamic studies of enrofloxacin. A good linear relationship between dosage and $\mathrm{AUC}_{0-24}$ was observed for enrofloxacin and ciprofloxacin. This phenomenon was similar to that reported in previous studies [21, 33].

Table 3 Pharmacokinetic parameters of ciprofloxacin in serum after oral administration of 1, 10, and $20 \mathrm{mg} / \mathrm{kg}$ body weight enrofloxacin in E. coli O78-infected chicks (mean and SD, $n=10$ )

\begin{tabular}{llll}
\hline Parameters & $1 \mathrm{mg} / \mathrm{kg}$ & $10 \mathrm{mg} / \mathrm{kg}$ & $20 \mathrm{mg} / \mathrm{kg}$ \\
\hline $\mathrm{C}_{\max }(\mu \mathrm{g} / \mathrm{mL})$ & $0.03 \pm 0.001$ & $0.10 \pm 0.03$ & $0.37 \pm 0.05$ \\
$\mathrm{~T}_{\max }(\mathrm{h})$ & $5 \pm 1.05$ & $4.3 \pm 1.98$ & $4.4 \pm 1.58$ \\
$\mathrm{~T}_{1 / 2 \beta}(\mathrm{h})$ & $27.25 \pm 7.76$ & $19.51 \pm 2.60$ & $18.77 \pm 4.11$ \\
$\mathrm{AUC}_{0-24}(\mathrm{~h} \cdot \mu \mathrm{g} / \mathrm{mL})$ & $0.61 \pm 0.03$ & $1.42 \pm 0.15$ & $4.93 \pm 0.76$ \\
$\mathrm{CL} / \mathrm{F}(\mathrm{mL} / \mathrm{h} / \mathrm{kg})$ & $0.67 \pm 0.11$ & $3.96 \pm 0.78$ & $2.26 \pm 0.46$ \\
\hline
\end{tabular}

$C_{\max }$ peak concentration, $T_{\max }$ time of peak concentration, $T_{1 / 2 \beta}$ elimination half-life, $A \cup C_{0-24}$ area under the concentration-time curve from 0 to $24 \mathrm{~h}, C L / F$ oral clearance
To the best of our knowledge, there has been no in vivo $\mathrm{PK} / \mathrm{PD}$ modeling study of enrofloxacin against $E$. coli in chicks. One of the best PK/PD parameter for fluoroquinolones is $\mathrm{AUC}_{0-24} / \mathrm{MIC}$ [34-36], and this study further confirmed this conclusion. Both the surrogate $\mathrm{AUC}_{0-24} / \mathrm{MIC}$ for enrofloxacin or the combination of enrofloxacin and ciprofloxacin correlated well with effectiveness in each organ. It seems that the metabolism of ciprofloxacin has little influence on the PK/PD modeling of enrofloxacin. However, whether the active metabolite plays a role in emerging resistance or has an impact on dosing optimization needs further investigation [37], because optimization of the dosing regimen involves not only maximizing therapeutic outcome, but also minimizing the risk of developing resistance [38-40]. The values of $\mathrm{AUC}_{0-24} / \mathrm{MIC}$ for the bactericidal effect were 19.3-32.15 in the different organs using only the concentration of enrofloxacin for simulation, and 21.2941.68 when using the combined concentrations of enrofloxacin and ciprofloxacin for simulation. The values were much lower than those of enrofloxacin against E. coli or Salmonella typhimurium in the intestinal content of infected chicken calculated from ex vivo PK/PD modeling (1065.93 and 719.33, respectively) $[14,16]$. Several reasons may explain this significant discrepancy. First, the components of the intestinal content are very complex, a large proportion of drugs may exist in a bound form and show no antimicrobial effect; however, in our PK/PD modeling, the whole amount of the drug was involved in the $\mathrm{AUC}_{0-}$ ${ }_{24} / \mathrm{MIC}$ calculation; therefore, the value of $\mathrm{AUC}_{0-24} / \mathrm{MIC}$ in the intestines may be higher than that in serum to achieve the same effect. Second, as reported previously, the discrepancy between ex vivo PK/PD modeling and in vivo PK/PD modeling was obvious [21].

Using the bacterial burden reduction in each organ as $\mathrm{PD}$ endpoints, the value of the $\mathrm{PK} / \mathrm{PD}$ parameter, $\mathrm{AUC}_{0-}$ 24/MIC, to attain the same effect was different. The $\mathrm{AUC}_{0-24} / \mathrm{MIC}$ value for the bactericidal effect in the liver was higher than that in lung, and twice than that in blood. This phenomenon was also observed in our previous study. The $\mathrm{AUC}_{0-24} / \mathrm{MIC}$ values of danofloxacin against Salmonella typhimurium for the same effect in different organs also showed marked differences [22]. Similar results were also reported in other studies [20,41]. The possible reason for these differences may lie in the differences in the initial bacterial load, the concentration diversity of drugs in each organ, and the complicated structures among different organs. The precise explanation requires further study. Usually, bacterial load reduction in a single organ is used for PD evaluation in most in vivo PK/PD studies, and for ex vivo PK/PD studies, the antibacterial effect of drugs in serum or other body fluid is used for PD calculation [12, 40, 42-47]. 

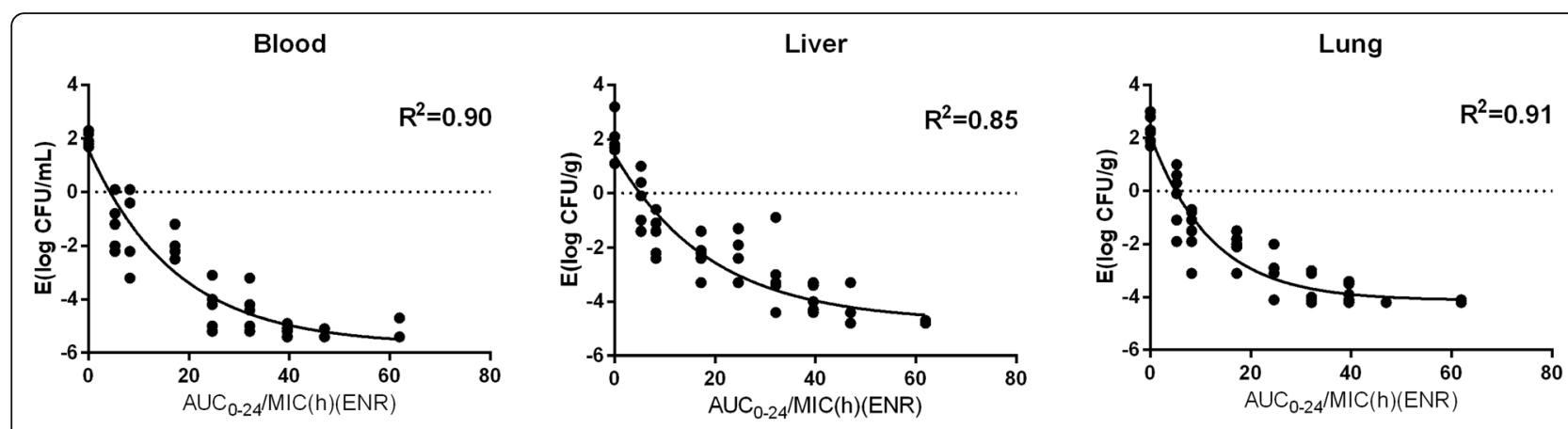

Fig. 3 Sigmoid maximum effect $\left(E_{\text {max }}\right)$ relationship between the in vivo antimicrobial effect against $E$. coli $O 78$ in three tissues of chicken and the area under the concentration-time curve from 0 to $24 \mathrm{~h}\left(\mathrm{AUC}_{0-24}\right) /$ minimum inhibitory concentration (MIC) ratio of enrofloxacin. [enrofloxacin (ENR)]

However, according to our results, for a systemic infection by bacteria, to describe the relationship of PK and PD exactly, bacterial loading reduction in different organs, as PD endpoints, should be compared in $\mathrm{PK} / \mathrm{PD}$ modeling and the selection of a target organ for $\mathrm{PD}$ evaluation is critical in rational dosage recommendation.

The results obtained using this model need to be validated by clinical trials in relevant animal species. However, it is still a critical step to increase our understanding of PK/PD relationships for antimicrobials. To simulate the clinical use of enrofloxacin, enrofloxacin was administrated via gavage in this study; however, the most recent basic principles of the prudent use of antimicrobials do not support the group oral administration of fluoroquinolones in animals.

\section{Conclusions}

In conclusion, an in vivo PK/PD model of enrofloxacin against $E$. coli in seven-day-old chicks was established using bacteria loading reduction in several organs as PD endpoints. The in vivo effectiveness of enrofloxacin against $E$. coli in different organs varied with $E_{\max }$ ranging from -4.4 to $-5.8 \log _{10} \mathrm{cfu} / \mathrm{mL}$. Both the surrogate $\mathrm{AUC}_{0-24} / \mathrm{MIC}$ of enrofloxacin or the combination
$\mathrm{AUC}_{0-24} / \mathrm{MIC}$ of enrofloxacin and ciprofloxacin correlated well with effectiveness in each organ. The combined $\mathrm{AUC}_{0-24} / \mathrm{MIC}$ ratios producing bactericidal and elimination effects were 21.29 and 32.13 in blood; 41.68 and 58.52 in liver; and 27.65 and 46.22 in lung, respectively. The magnitude of $\mathrm{PK} / \mathrm{PD}$ index was lowest for the same effect in blood, but highest in the liver, indicating that at the same dosage, the in vivo effectiveness of enrofloxacin against $E$. coli in different organs was not identical. This study emphasized the importance of target organ selection for PD evaluation in PK/PD modeling.

\section{Methods}

Organisms, chemicals, and animals

The clinical E. coli O78 strain, which was used in our previous study, was isolated from a broiler showing colibacillosis $[23,48]$. The quality control standard E. coli strain ATCC 25922 was purchased from the Chinese Veterinary Culture Collection. The enrofloxacin reference standard and ciprofloxacin (98\% purity) were purchased from Solarbio Life Sciences Co. Ltd. (Beijing, China). Acetonitrile (ACN) and methanol $(\mathrm{MeOH})$ were purchased from TEDIA (Fairfield, CT, USA). All reagents used in this experiment were of high

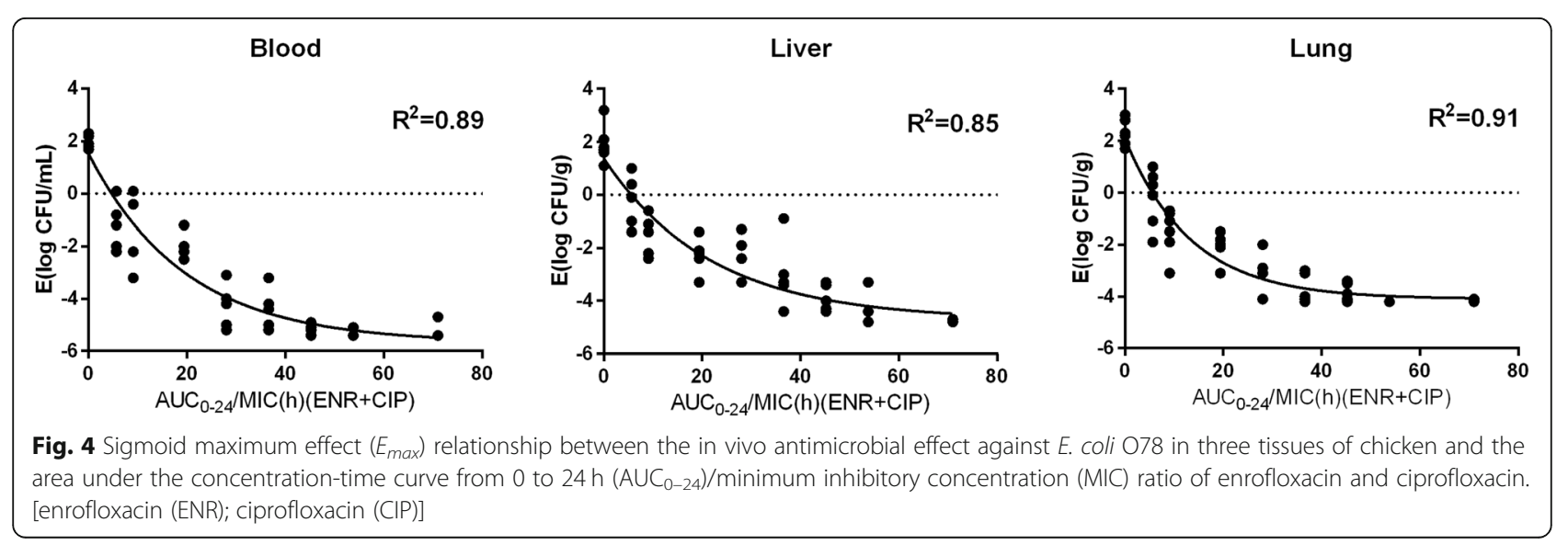


Table 4 In vivo PK/PD parameters of enrofloxacin in E. coli O78infected chicks using the concentration of enrofloxacin for simulation

\begin{tabular}{llll}
\hline Parameters & Blood & Liver & Lung \\
\hline$E_{\text {max }}\left(\log { }_{10} \mathrm{cfu} / \mathrm{mL}\right)$ & -5.8 & -4.7 & -4.4 \\
$\mathrm{EC}_{50}$ & 16.61 & 16.93 & 10.33 \\
$E_{0}\left(\mathrm{Log}_{10} \mathrm{Cfu} / \mathrm{mL}\right)$ & 1.78 & 1.68 & 2.29 \\
AUC $_{0-24} / \mathrm{MIC}$ for $1 \log _{10} \mathrm{cfu} / \mathrm{mL}$ killing & 9.29 & 12.42 & 9.1 \\
AUC $_{0-24} / \mathrm{MIC}$ for $3 \log _{10} \mathrm{cfu} / \mathrm{mL}$ killing & 19.32 & 32.15 & 23.41 \\
AUC $_{0-24} / \mathrm{MIC}$ for $4 \log _{10} \mathrm{cfu} / \mathrm{mL}$ killing & 28.17 & 52.52 & 56.36 \\
Slope $(\mathrm{N})$ & 2.58 & 2.36 & 3.01 \\
\hline
\end{tabular}

$E_{\max }$ maximum effect, $E C_{50}$ concentration of a drug that gives half-maximal response, $E_{0}$ concentration at baseline, $A \cup C_{0-24}$ area under the concentrationtime curve from 0 to $24 \mathrm{~h}$, cfu colony forming units

performance liquid chromatography (HPLC) grade. The culture medium used in this experiment was purchased from Hope Biol-Technology Co. Ltd. (Qingdao, China). One-day-old healthy broilers $(n=324)$, obtained from the Jiangsu Institute of Poultry Sciences (Yangzhou, China), were used in this study. These broilers were mixed sex (50:50), weighting from 35.2 to $45.6 \mathrm{~g}$. A six-day acclimation period was set for animals before the study. The animals were maintained according to the National Standards for Laboratory Animals of China (GB 14925-2010). This study was approved by the Animal Experiments Ethics Committee at Yangzhou University (SYXK (Su) IACUC 2017-0045).

\section{Susceptibility testing}

The MICs of enrofloxacin and ciprofloxacin against $E$. coli $\mathrm{O} 78$ and ATCC 25922 were determined using the micro-dilution method, according to the Clinical and Laboratory Standards Institute (CLSI) reference method [49]. The MIC of enrofloxacin in serum was also

Table 5 In vivo PK/PD parameters of enrofloxacin in E. coli O78infected chicks using the combined concentration of enrofloxacin and ciprofloxacin for simulation

\begin{tabular}{llll}
\hline Parameters & Blood & Liver & Lung \\
\hline$E_{\text {max }}(\log 10 \mathrm{cfu} / \mathrm{mL})$ & -5.8 & -4.7 & -4.4 \\
$\mathrm{EC}_{50}$ & 18.28 & 17.66 & 13.59 \\
$E_{0}\left(\log { }_{10} \mathrm{Cfu} / \mathrm{mL}\right)$ & 1.78 & 1.68 & 2.29 \\
AUC $_{0-24} / \mathrm{MIC}$ for $1 \log _{10} \mathrm{cfu} / \mathrm{mL}$ killing & 9.74 & 14.01 & 9.49 \\
$\mathrm{AUC}_{0-24} / \mathrm{MIC}$ for $3 \log _{10} \mathrm{cfu} / \mathrm{mL}$ killing & 21.29 & 41.68 & 27.65 \\
AUC $_{0-24} / \mathrm{MIC}$ for $4 \log _{10} \mathrm{cfu} / \mathrm{mL}$ killing & 32.13 & 60.52 & 57.24 \\
Slope $(\mathrm{N})$ & 4.19 & 2.67 & 4.86 \\
\hline
\end{tabular}

$E_{\text {max }}$ maximum effect, $E C_{50}$ concentration of a drug that gives half-maximal response, $E_{O}$ concentration at baseline, $A U C_{0-24}$ area under the concentrationtime curve from 0 to $24 \mathrm{~h}$, cfu colony forming units determined using the micro-dilution method according to a previous report [50]. To determine the minimum bactericidal concentration (MBC), $100 \mu \mathrm{L}$ aliquots from the MIC determination procedure were diluted with Mueller-Hinton $(\mathrm{MH})$ broth. The colony forming units (cfu) of each dilution were counted by spreading $100 \mu \mathrm{L}$ dilutions on $\mathrm{MH}$ agar plates after $24 \mathrm{~h}$ of incubation at $37^{\circ} \mathrm{C}$. The lowest concentration of enrofloxacin that killed $99.9 \%$ of the bacteria was defined as the MBC. The mutant prevention concentration (MPC) determination was conducted according to a previous report [51]. Briefly, a series $\mathrm{MH}$ agar plates containing different drug concentrations (1 MIC to $64 \mathrm{MIC}$ ) were inoculated with more than $10^{10} \mathrm{cfu}$ of E. coli and then incubated at $37^{\circ} \mathrm{C}$ for $72 \mathrm{~h}$. The MPC was determined as the lowest drug concentration that prevented bacterial growth.

\section{E. coli infection model}

Preliminary experiments were conducted to confirm the inoculation amount. After a 6-day acclimation period, broilers were inoculated with $0.5 \mathrm{~mL}$ of $E$. coli culture containing $\sim 10^{7} \mathrm{cfu} / \mathrm{mL}$ through intramuscular injection (IM) in the chest muscle. The clinical symptoms and pathological changes were observed. Then, animals were sacrificed by a lethal intravenous injection of beuthanasia $(0.3 \mathrm{~mL} / \mathrm{kg})$ after anesthesia with ketamine-Xylazine. The bacterial load in blood, liver, and lung were determined by the agar plate dilution method at $24 \mathrm{~h}$ post inoculation.

\section{Pharmacokinetics}

Enrofloxacin was administered orally to 280 infected broilers at doses of 1,10 , and $20 \mathrm{mg} / \mathrm{kg}$ body weight (b.w.). Ten blood samples were collected at each time point $(0,0.5,1,1.5,2,4,6,8,12$, and $24 \mathrm{~h}$ after administration). After sampling, animals were narcotized with ketamine-Xylazine and sacrificed by a lethal intravenous injection of beuthanasia $(0.3 \mathrm{~mL} / \mathrm{kg})$. After incubation at room temperature, samples were centrifuged for $10 \mathrm{~min}$ at $3000 \times g$ to obtain serum. The serum was stored at $-20^{\circ} \mathrm{C}$ until analysis. The concentrations of the drug in the serum were determined using HPLC with a fluorescence detector, as described previously, with some modifications [17, 52]. Briefly, $0.1 \mathrm{~mL}$ of serum was added to $1 \mathrm{~mL}$ of ACN containing $0.1 \%$ acetic acid, vortexed for $3 \mathrm{~min}$, and then centrifuged at $12000 \times g$ for $10 \mathrm{~min}$. The supernatant was transferred to a clean tube, dried under nitrogen, and re-dissolved with $0.1 \mathrm{~mL} 17 \% \mathrm{ACN}$. The sample was filtered through a $0.22-\mu \mathrm{m}$ membrane before injecting into the HPLC apparatus. The recovery rate was between 80.2 and $91.3 \%$, and the intra and inter coefficient of variation was less than $7 \%$. The serum concentration-time data of enrofloxacin and 
ciprofloxacin for each animal was used to calculate the PK parameters in broilers using the WinNonlin software (version 6.1, Pharsight Corporation, Mountain View, CA, USA).

\section{Pharmacodynamics determination}

Infected broilers $(n=54)$ were randomly divided into nine groups ( $n=6$ in each group) and treated with enrofloxacin for 3 successive days at doses ranging from 0 to $20 \mathrm{mg} / \mathrm{kg}$ b.w. (0, 1, 2, 5, 7.5, 10, 12.5, 15, and $20 \mathrm{mg} / \mathrm{kg}$ per day). At $24 \mathrm{~h}$ after the last dose, the broilers were humanely killed through a lethal intravenous injection of beuthanasia $(0.3 \mathrm{~mL} / \mathrm{kg})$ after anesthesia with ketamine-Xylazine to collect blood, liver, and lung samples. The bacterial loading in each organ was determined via plating dilutions onto $\mathrm{MH}$ agar and counting the colonies after incubation at $37^{\circ} \mathrm{C}$ for $24 \mathrm{~h}$. The effectiveness of enrofloxacin was expressed as the bacterial reduction after treatment compared with that before treatment in each organ.

\section{Pharmacokinetics and Pharamcodynamics integration and modeling}

The best PK/PD parameter for fluoroquinolones is AUC/MIC or $\mathrm{C}_{\max } / \mathrm{MIC}$; therefore, in the present study, we chose the $\mathrm{AUC}_{0-24} / \mathrm{MIC}$ method to model the PK data and in vitro PD data for enrofloxacin and its active metabolite ciprofloxacin. The sigmoid $E_{\max }$ model in the WinNonlin software (version 6.1; Pharsight) was used to simulate the relationship between $\mathrm{AUC}_{0-24} / \mathrm{MIC}$ of enrofloxacin, or the combination $\mathrm{AUC}_{0-24} / \mathrm{MIC}$ of enrofloxacin and ciprofloxacin and in vivo effectiveness. The equation for this model was as follows:

$$
E=E_{0}+\frac{E_{\max } \times C_{e}^{N}}{E C_{50}^{N}+C_{e}^{N}}
$$

In the above formula, $E_{0}$ is the change in $\log _{10} \mathrm{cfu} / \mathrm{mL}$ or $\log _{10} \mathrm{cfu} / \mathrm{g}$ in the control sample (absence of drug). $E_{\text {max }}$ is the difference in effect between the greatest amount of growth (as seen for the growth control, $\mathrm{E}_{0}$ ) and the greatest amount of killing. $\mathrm{C}_{\mathrm{e}}$ is the tested $\mathrm{AUC}_{0-24} / \mathrm{MIC}$ ratio; $\mathrm{EC}_{50}$ is the $\mathrm{AUC}_{0-24} / \mathrm{MIC}$ value that reached $50 \%$ of the $E_{\text {max }}$; and $\mathrm{N}$ is the Hill coefficient that describes the steepness of the $\mathrm{AUC}_{0-24} /$ MIC-effect curve [52]. The in vivo antibacterial effects of enrofloxacin were quantified into three levels including: (1) $1 \log 10 \mathrm{cfu} / \mathrm{mL}$ killing $(\mathrm{E}=-1)$, (2) bactericidal action (99.9\% reduction, $\mathrm{E}=-3$ ), and (3) bacterial elimination $(99.99 \%$ reduction, $\mathrm{E}=-4$ ).

\section{Data analysis}

The PK data, PK/PD data, and PK/PD curve fitting were analyzed using the WinNonlin software (version 6.1;
Pharsight). T-tests were conducted for other data using SPSS software (IBM, Armonk, NY, USA). $P<0.05$ was considered statistically significant.

\section{Abbreviations}

ACN: Acetonitrile; $\mathrm{AUC}_{0-24}$ : Area under the concentrations-time curve from 0 to 24 h; CLSI: Clinical and Laboratory Standards Institute; $\mathrm{CL}_{\beta} / \mathrm{F}$ : Clearance divided by bioavailability; $C_{\text {max }}$ : Maximum serum concentration;

F: Bioavailability; HPLC: High performance liquid chromatography; MBC: Minimum bactericidal concentration; $\mathrm{MeOH}$ : Methanol; MIC: Minimum inhibitory concnetration; MPC: Mutant prevention cocnetration; PK PD: Pharmacokinetic/pharmacodynamic; $T_{1 / 2 \beta}$ : Elimination half-life; $T_{\text {max }}$ : Time of maximum serum concentration; $V_{z} / F$ : Volume of distribution scaled by bioavailability

\section{Acknowledgements}

Not applicable.

\section{Funding}

This work was funded by the National Key Research and Development Program of China (grant number 2016YFD0501310) in the design of the study; it was also supported by the National Natural Science Foundation of China (grant numbers 31702291, 31872526) in collection, analysis and interpretation of data and writing the manuscript; The Priority Academic Program Development of Jiangsu Higher Education Institutions, P. R. China, also paid publication charges for this article.

\section{Availability of data and materials}

The datasets used and/or analysed during the current study are available from the corresponding author on reasonable request.

\section{Authors' contributions}

$X X$ and ZW designed this study and revised and guided the experiment. XX wrote this manuscript and participated in the whole experiment process; $L J$ managed the whole experiment and analyzed the data; $L J$ and $W L$ participated all the experiments; $W L$ and $Y J$ helped for the sampling process and concentration detection. All authors read and approved the final manuscript.

\section{Ethics approval and consent to participate}

The animals were maintained according to the National Standards for Laboratory Animals of China (GB 14925-2010). This study was approved by the Animal Experiments Ethics Committee at Yangzhou University (SYXK(Su) IACUC 2017-0045).

Consent for publication

Not applicable.

Competing interests

The authors declare that they have no competing interests.

\section{Publisher's Note}

Springer Nature remains neutral with regard to jurisdictional claims in published maps and institutional affiliations.

\section{Author details}

${ }^{1}$ College of Veterinary Medicine, Yangzhou University, Yangzhou 225009, Jiangsu, People's Republic of China. ${ }^{2}$ Jiangsu Co-innovation Center for Prevention and Control of Important Animal Infectious Diseases and Zoonoses, Yangzhou, Jiangsu 225009, People's Republic of China. ${ }^{3}$ Institutes of Agricultural Science and Technology Development, 48 East Wenhui Road, Yangzhou, Jiangsu 225009, People's Republic of China.

Received: 6 February 2018 Accepted: 19 November 2018 Published online: 29 November 2018

\section{References}

1. Yassin $H$, Velthuis AG, Boerjan $M$, van Riel J. Field study on broilers' firstweek mortality. Poult Sci. 2009;88(4):798-804. 
2. Olsen RH, Frantzen C, Christensen H, Bisgaard M. An investigation on firstweek mortality in layers. Avian Dis. 2012;56(1):51-7.

3. Kemmett K, Williams NJ, Chaloner G, Humphrey S, Wigley P, Humphrey T. The contribution of systemic Escherichia coli infection to the early mortalities of commercial broiler chickens. Avian Pathol. 2014:43(1):37-42.

4. Dziva F, Hauser H, Connor TR, van Diemen PM, Prescott G, Langridge GC, Eckert S, Chaudhuri RR, Ewers C, Mellata M, et al. Sequencing and functional annotation of avian pathogenic Escherichia coli serogroup 078 strains reveal the evolution of E. coli lineages pathogenic for poultry via distinct mechanisms. Infect Immun. 2013;81(3):838-49,

5. Salvadori M, Vercelli C, De Vito V, Dezzutto D, Bergagna S, Re G, Giorgi M. Pharmacokinetic and pharmacodynamic evaluations of a $10 \mathrm{mg} / \mathrm{kg}$ enrofloxacin intramuscular administration in bearded dragons (Pogona vitticeps): a preliminary assessment. J Vet Pharmacol Ther. 2017:40(1):62-9.

6. Pallo-Zimmerman LM, Byron JK, Graves TK. Fluoroquinolones: then and now. Compendium. 2010;32(7):E1-9 quiz E9.

7. Vanni M, Meucci V, Tognetti R, Cagnardi P, Montesissa C, Piccirillo A, Rossi AM, Di Bello D, Intorre L. Fluoroquinolone resistance and molecular characterization of gyrA and parC quinolone resistance-determining regions in Escherichia coli isolated from poultry. Poult Sci. 2014;93(4):856-63.

8. Dheilly A, Le Devendec L, Mourand G, Jouy E, Kempf I. Antimicrobial resistance selection in avian pathogenic E. coli during treatment. Vet Microbiol. 2013;166(3-4):655-8.

9. Dheilly A, Le Devendec L, Mourand G, Bouder A, Jouy E, Kempf I. Resistance gene transfer during treatments for experimental avian colibacillosis. Antimicrob Agents Chemother. 2012;56(1):189-96.

10. Ma R, Yang L, Ren T, Dong Y, Liu T, Zhuang P, Fang W, Yang X, Hu K. Enrofloxacin pharmacokinetics in Takifugu flavidusafter oral administration at three salinity levels. Aquac Res. 2017;48(8):4545-53.

11. Phu TM, Phuong NT, Scippo ML, Dalsgaard A. Quality of antimicrobial products used in striped catfish (Pangasianodon hypophthalmus) aquaculture in Vietnam. PLoS One. 2015;10(4):e0124267.

12. Koc F, Uney K, Ozturk M, Kadioglu Y, Atila A. Pharmacokinetics of florfenicol in the plasma of Japanese quail. N Z Vet J. 2009;57(6):388-91.

13. Aliabadi FS, Ali BH, Landoni MF, Lees P. Pharmacokinetics and PK-PD modelling of danofloxacin in camel serum and tissue cage fluids. Vet $\mathrm{J}$. 2003;165(2):104-18.

14. Li J, Hao H, Cheng G, Wang X, Ahmed S, Shabbir MAB, Liu Z, Dai M, Yuan Z. The effects of different enrofloxacin dosages on clinical efficacy and resistance development in chickens experimentally infected with Salmonella typhimurium. Sci Rep. 2017;7(1):11676.

15. Wang J, Hao H, Huang L, Liu Z, Chen D, Yuan Z. Pharmacokinetic and Pharmacodynamic integration and modeling of Enrofloxacin in swine for Escherichia coli. Front Microbiol. 2016;7:36.

16. Sang $\mathrm{K}$, Hao H, Huang L, Wang $X$, Yuan Z. PharmacokineticPharmacodynamic modeling of Enrofloxacin against Escherichia coli in broilers. Frontiers in veterinary science. 2015;2:80.

17. Ramalingam B, Sidhu PK, Kaur G, Venkatachalam D, Rampal S. Mutant prevention concentration, pharmacokinetic-pharmacodynamic integration, and modeling of enrofloxacin data established in diseased buffalo calves. Vet Pharmacol Ther. 2015;38(6):529-36.

18. Daundkar PS, Vemu B, Dumka VK, Sharma SK. Pharmacokineticpharmacodynamic integration of enrofloxacin and its metabolite ciprofloxacin in buffalo calves. Vet Med Sci. 2015;1(2):63-71.

19. Balaje RM, Sidhu PK, Kaur G, Rampal S. Mutant prevention concentration and PK-PD relationships of enrofloxacin for Pasteurella multocida in buffalo calves. Res Vet Sci. 2013;95(3):1114-24.

20. Haritova A, Urumova V, Lutckanov M, Petrov V, Lashev L. Pharmacokineticpharmacodynamic indices of enrofloxacin in Escherichia coli O78/H12 infected chickens. Food Chem Toxicol. 2011;49(7):1530-6.

21. Xiao X, Sun J, Yang T, Fang X, Wu D, Xiong YQ, Cheng J, Chen Y, Shi W, Liu $Y H$. In vivo pharmacokinetic/pharmacodynamic profiles of valnemulin in an experimental intratracheal mycoplasma gallisepticum infection model. Antimicrob Agents Chemother. 2015;59(7):3754-60.

22. Xiao $X$, Pei $L$, Jiang $L$, Lan $W X$, Xiao JY, Jiang YJ, Wang ZQ. In Vivo Pharmacokinetic/Pharmacodynamic Profiles of Danofloxacin in Rabbits Infected With Salmonella typhimurium After Oral Administration. Front Pharmacol. 2018;9:391.

23. Xiao X, Sun J, Chen Y, Zou M, Zhao DH, Liu YH. Ex vivo pharmacokinetic and pharmacodynamic analysis of valnemulin against mycoplasma gallisepticum S6 in mycoplasma gallisepticum and Escherichia coli coinfected chickens. Vet J. 2015:204(1):54-9.

24. Elmas M, Tras B, Kaya S, Bas AL, Yazar E, Yarsan E. Pharmacokinetics of enrofloxacin after intravenous and intramuscular administration in angora goats. Can J Vet Res. 2001;65(1):64-7.

25. McKellar Q, Gibson I, Monteiro A, Bregante M. Pharmacokinetics of enrofloxacin and danofloxacin in plasma, inflammatory exudate, and bronchial secretions of calves following subcutaneous administration. Antimicrob Agents Chemother. 1999;43(8):1988-92.

26. Anadon A, Martinez-Larranaga MR, Diaz MJ, Fernandez-Cruz ML, Martinez MA, Frejo MT, Martinez M, Iturbe J, Tafur M. Pharmacokinetic variables and tissue residues of enrofloxacin and ciprofloxacin in healthy pigs. Am J Vet Res. 1999;60(11):1377-82.

27. Giguere S, Sweeney RW, Belanger M. Pharmacokinetics of enrofloxacin in adult horses and concentration of the drug in serum, body fluids, and endometrial tissues after repeated intragastrically administered doses. Am J Vet Res. 1996;57(7):1025-30.

28. Kaartinen L, Salonen M, Alli L, Pyorala S. Pharmacokinetics of enrofloxacin after single intravenous, intramuscular and subcutaneous injections in lactating cows. J Vet Pharmacol Ther. 1995;18(5):357-62.

29. Guo QJ, Huang LL, Fang K, Wang YL, Chen DM, Tao YF, Dai MH, Liu ZL, Peng DP, Yuan ZH. Population pharmacokinetics of enrofloxacin and its metabolite ciprofloxacin in chicken based on retrospective data, incorporating first-pass metabolism. J Vet Pharmacol Ther. 2010;33(1):84-94.

30. da Silva RG, Reyes FG, Sartori JR, Rath S. Enrofloxacin assay validation and pharmacokinetics following a single oral dose in chickens. J Vet Pharmacol Ther. 2006;29(5):365-72.

31. Garcia Ovando H, Gorla N, Luders C, Poloni G, Errecalde C, Prieto G, Puelles I. Comparative pharmacokinetics of enrofloxacin and ciprofloxacin in chickens. J Vet Pharmacol Ther. 1999:22(3):209-12.

32. Mekala $P$, Jagadeeswaran $A$, Arivuchelvan $A$, Sethilkumar $P$, Nanjappan $K$, Krishnamurthy TRG. Comparison of pharmacokinetics of Enrofloxacin after single Oral bolus and pulse dose Administration in Broiler Chicken. Proc Nat Acad Sci India Sect B. 2015;87(3):679-83.

33. Schneider M, Paulin A, Dron F, Woehrle F. Pharmacokinetics of marbofloxacin in pigs after intravenous and intramuscular administration of a single dose of $8 \mathrm{mg} / \mathrm{kg}$ : dose proportionality, influence of the age of the animals and urinary elimination. J Vet Pharmacol Ther. 2014;37(6):523-30.

34. Zeng QL, Mei X, Su J, Li XH, Xiong WG, Lu Y, Zeng ZL. Integrated pharmacokinetic-Pharmacodynamic (PK/PD) model to evaluate the in vivo antimicrobial activity of Marbofloxacin against Pasteurella multocida in piglets. BMC Vet Res. 2017;13(1):178.

35. Dorey L, Pelligand L, Lees P. Prediction of marbofloxacin dosage for the pig pneumonia pathogens Actinobacillus pleuropneumoniae and Pasteurella multocida by pharmacokinetic/pharmacodynamic modelling. BMC Vet Res. 2017;13(1):209.

36. Xu L, Wang H, Yang X, Lu L. Integrated pharmacokinetics/ pharmacodynamics parameters-based dosing guidelines of enrofloxacin in grass carp Ctenopharyngodon idella to minimize selection of drug resistance. BMC Vet Res. 2013;9:126.

37. Zhang B, Gu X, Li Y, Li X, Gu M, Zhang N, Shen X, Ding H. In vivo evaluation of mutant selection window of cefquinome against Escherichia coli in piglet tissue-cage model. BMC Vet Res. 2014;10:297.

38. Mouton JW, Ambrose PG, Canton R, Drusano GL, Harbarth S, MacGowan A, Theuretzbacher U, Turnidge J. Conserving antibiotics for the future: new ways to use old and new drugs from a pharmacokinetic and pharmacodynamic perspective. Drug Resista Updat. 2011;14(2):107-17.

39. Ambrose PG, Bhavnani SM, Rubino CM, Louie A, Gumbo T, Forrest A, Drusano GL. Pharmacokinetics-pharmacodynamics of antimicrobial therapy: it's not just for mice anymore. Clin Infect Dis. 2007;44(1):79-86.

40. Toutain PL, Lees P. Integration and modelling of pharmacokinetic and pharmacodynamic data to optimize dosage regimens in veterinary medicine. J Vet Pharmacol Ther. 2004;27(6):467-77.

41. Swanson RV, Adamson J, Moodley C, Ngcobo B, Ammerman NC, Dorasamy A, Moodley S, Mgaga Z, Tapley A, Bester LA, et al. Pharmacokinetics and pharmacodynamics of clofazimine in a mouse model of tuberculosis. Antimicrob Agents Chemother. 2015;59(6):3042-51.

42. Ahmad I, Hao H, Huang L, Sanders P, Wang X, Chen D, Tao Y, Xie S, Xiuhua $\mathrm{K}, \mathrm{Li}$ J, et al. Integration of PK/PD for dose optimization of Cefquinome against Staphylococcus aureus causing septicemia in cattle. Front Microbiol. 2015;6:588. 
43. Khan DD, Friberg LE, Nielsen El. A pharmacokinetic-pharmacodynamic (PKPD) model based on in vitro time-kill data predicts the in vivo PK/PD index of colistin. J Antimicrob Chemother. 2016;71(7):1881-4.

44. Hawkins MG, Taylor IT, Byrne BA, Armstrong RD, Tell LA. Pharmacokineticpharmacodynamic integration of orbifloxacin in Japanese quail (Coturnix japonica) following oral and intravenous administration. J Vet Pharmacol Ther. 2011;34(4):350-8.

45. Zhang B, Gu X, Li X, Gu M, Zhang N, Shen X, Li Y, Ding H. Pharmacokinetics and ex-vivo pharmacodynamics of cefquinome against Klebsiella pneumonia in healthy dogs. J Vet Pharmacol Ther. 2014;37(4):367-73.

46. Govendir M. Review of some pharmacokinetic and pharmacodynamic properties of anti-infective medicines administered to the koala (Phascolarctos cinereus). J Vet Pharmacol Ther. 2017.

47. Haritova AM, Rusenova NV, Parvanov PR, Lashev LD, Fink-Gremmels J. Integration of pharmacokinetic and pharmacodynamic indices of marbofloxacin in turkeys. Antimicrob Agents Chemother. 2006;50(11): 3779-85.

48. Xiao X, Zhao DH, Yang X, Shi W, Deng H, Ma J, Zhang S, Liu YH Mycoplasma gallisepticum and Escherichia coli mixed infection model in broiler chickens for studying valnemulin pharmacokinetics. J Vet Pharmacol Ther. 2014;37(1):99-102.

49. CLSI: Performance Standards for Antimicrobial Disk and DilutionSusceptibility Tests for Bacteria Isolated From Animals: Approved Standard. 3rd Edition 2008:M31-A33.28(38).

50. Zhao DH, Zhou YF, Yu Y, Shi W, Yang X, Xiao X, Deng H, Qiao GG, Fang BH, Liu YH. Integration of pharmacokinetic and pharmacodynamic indices of valnemulin in broiler chickens after a single intravenous and intramuscular administration. Vet J. 2014;201(1):109-15.

51. Cao C, Qu Y, Sun M, Qiu Z, Huang X, Huai B, Lu Y, Zeng Z. In vivo antimicrobial activity of marbofloxacin against Pasteurella multocida in a tissue cage model in calves. Front Microbiol. 2015;6:759.

52. Burton ME, Shaw LM, Schentag JJ, Evans WE. Applied Pharmacokinetics \& Pharmacodynamics: principles of therapeutic drug monitoring. Philadelphia: Lippincott Williams and Wilkins Press; 2005. p. 61-5.

Ready to submit your research? Choose BMC and benefit from:

- fast, convenient online submission

- thorough peer review by experienced researchers in your field

- rapid publication on acceptance

- support for research data, including large and complex data types

- gold Open Access which fosters wider collaboration and increased citations

- maximum visibility for your research: over $100 \mathrm{M}$ website views per year

At $\mathrm{BMC}$, research is always in progress.

Learn more biomedcentral.com/submissions 